\title{
Health Surveillance of Forestry Workers Exposed to Hand-Arm Vibration in Wakayama from 1974 to 1996
}

\author{
Kazuhisa MIYASHITA ${ }^{1 *}$, Kotaro TOMIDA ${ }^{1}$, Ikuharu MORIOKA ${ }^{1}$, \\ Takeshi SASAKI ${ }^{1}$ and Hirotoshi IWATA ${ }^{2}$
}

\author{
' Department of Hygiene, Wakayama Medical University, School of Medicine, 27, Kyubancho, Wakayama 640- \\ 8155, Japan \\ ${ }^{2}$ Department of Hygiene, Gifu University, School of Medicine, 40, Tsukasamachi, Gifu 500-8076, Japan
}

Received November 14, 1997 and accepted January 12, 1998

\begin{abstract}
To clarify the trends in the number and the severity of vibration syndrome in Wakayama for these 23 years, the records of the medical examinations for vibration syndrome were analyzed with 4,652 (a total of 9,920) private forestry workers exposed to hand-arm vibration. The number of the subjects who took the medical examinations reached a maximum of 1,242 in 1978. After that, it decreased year by year, but remained at about 300 or less from 1988. There was a corresponding increase in age and the number of years of operating chain saws among the subjects examined. The compensated cases reached a maximum number of 393 cases in 1977, and then a drastic decrease was noted. Year by year there was an increase in the number of cases whose medical examinations revealed no abnormality. The regional occupational health care system including the surveillance card, which has been active since 1975, has probably contributed to the decrease or prevention of occurrence of vibration syndrome in Wakayama.
\end{abstract}

Key words: Health surveillance, Forestry workers, Hand-arm vibration, Health care system, Vibration syndrome

\section{Introduction}

Vibration syndrome was first reported in Japan in the latter half of the 1930's'. In the 1960's the national forestry workers suffered from "white finger attack" (Raynaud's phenomenon of occupational origin) as a result of operating chain saws in Japanese forests ${ }^{1)}$. The occurrence of vibration syndrome had been increasing as the various types of vibrating tools, including chain saws, spread to a wide range of industrial fields in a short time since the latter half of the 1960's ${ }^{1}$. The occupational medical examinations for vibration syndrome in Japan were documented in 1970, and revised in 1975 by the Ministry of Labour ${ }^{2}$.

In Wakayama, there have been many private forestry workers. The first case suffering from vibration syndrome was reported in 1970 's ${ }^{1}$. Under these circumstances, the

*To whom correspondence should be addressed. counterplan against vibration syndrome was practiced earlier in Wakayama than all over the country. The occupational medical examinations were first carried out in 1974. The regional occupational health care system on vibration syndrome has been established in Wakayama since $1975^{3}$. Now that more than 20 years have passed, the vibrating tools have been improved to reduce the level of vibration. In this report, the health conditions of private forestry workers have been surveyed to clarify the trends in the number and the severity of vibration syndrome in Wakayama for the past 23 years.

\section{Methods}

The subjects examined were 4,652 (a total of 9,920) workers in the private forestry industry who received occupational medical examinations for vibration syndrome under the regional occupational health care system in 


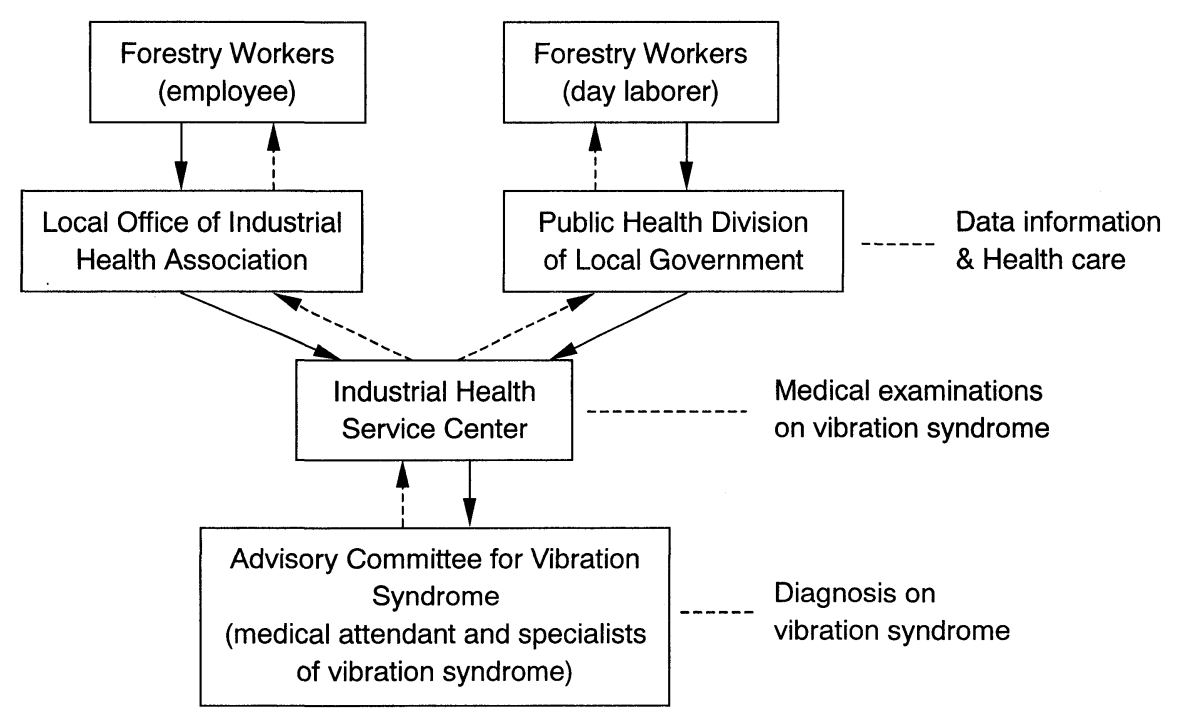

Fig. 1. Diagram of the regional occupational health care system

Wakayama from 1974 to 1996.

Here, we briefly summarize the regional occupational health care system for private forestry workers exposed to hand-arm vibration in Wakayama (Fig. 1). The local office of the Industrial Health Association and the public health division of the local government arrange annual medical examinations for vibration syndrome among private forestry workers. Medical staff conduct the medical examinations at a workshop. The results of the medical examinations are forwarded to the Industrial Health Service Center. A diagnosis is made by the Advisory Committee for vibration syndrome which includes a medical attendant and specialists of vibration syndrome. The health condition and the advice concerning health of the forestry workers are then conveyed personally to the forestry worker by either the local office of the Industrial Health Association or the public health division of the local government.

The medical examinations for vibration syndrome consist of analysis of working career, working conditions, and physical examinations of the subjects concerned. "Working career" means not only the number of years spent working in the forest, but also the number of years spent operating vibrating tools and the various kinds of tools used. "Working conditions" refers to working environmental conditions, how to attend workshops and the payment system. "Physical examinations" involves a primary examination and a secondary examination to determine peripheral circulatory disturbances, peripheral nerve disturbances and motor disturbances.

A diagnosis on vibration syndrome is made by the Advisory
Table 1. Classification of health conditions for vibration syndrome

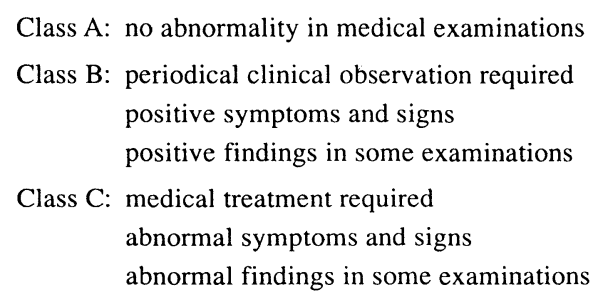

Committee for vibration syndrome. Considering the results of the medical examinations, the diagnoses are classified into three health conditions for vibration syndrome; Class A (no abnormality in medical examinations), Class B (periodical clinical observation required), Class $\mathrm{C}$ (medical treatment required) (Table 1). All records of the medical examinations for vibration syndrome are kept in the Industrial Health Service Center.

In this report, the records of the medical examinations for vibration syndrome of all subjects were analyzed to clarify the trends in the number of the subjects and the severity of vibration syndrome experienced by the subjects examined.

\section{Results}

The number of the subjects who took medical examinations for vibration syndrome is shown in Figure 2. In 1978, the number of the subjects was a maximum of 1,242. After 


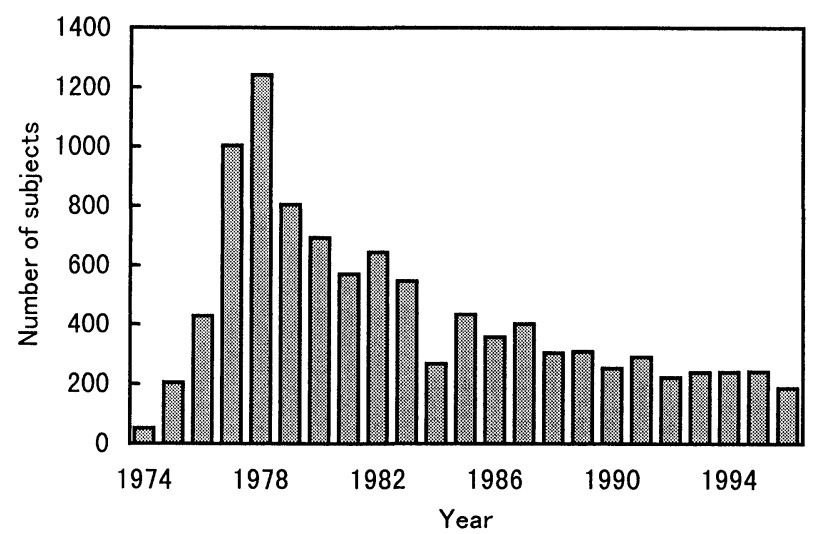

Fig. 2. The number of the subjects who took the medical examinations for vibration syndrome
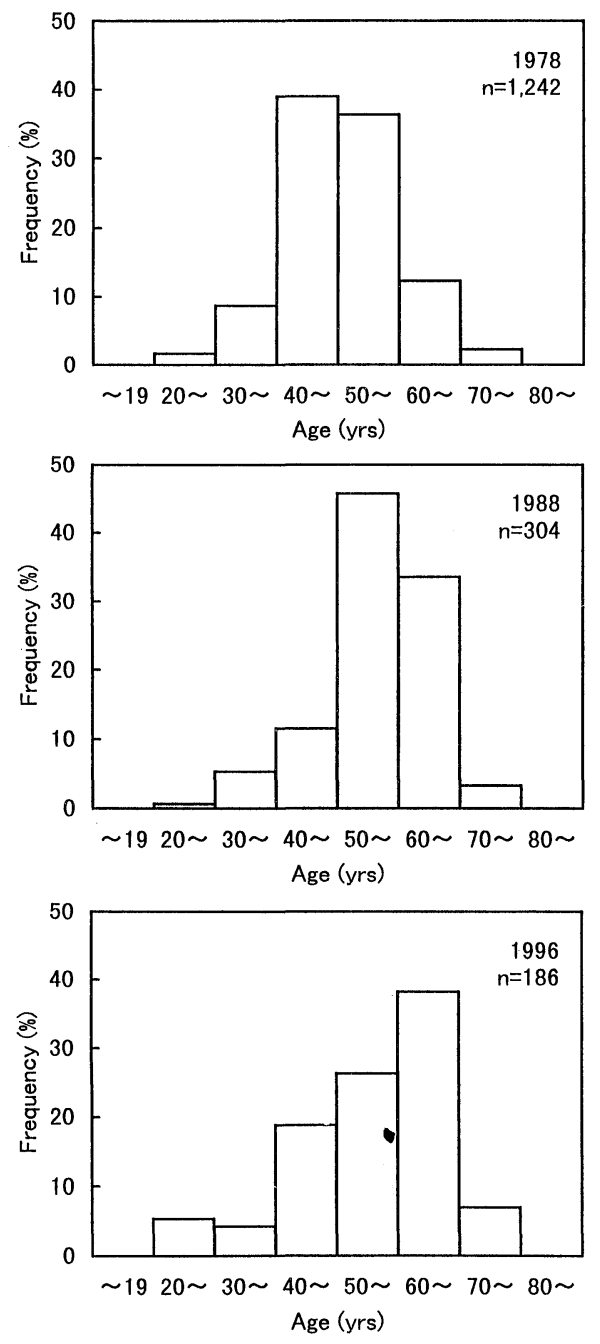

Fig. 3. Age composition of the subjects in 1978, 1988 and 1996

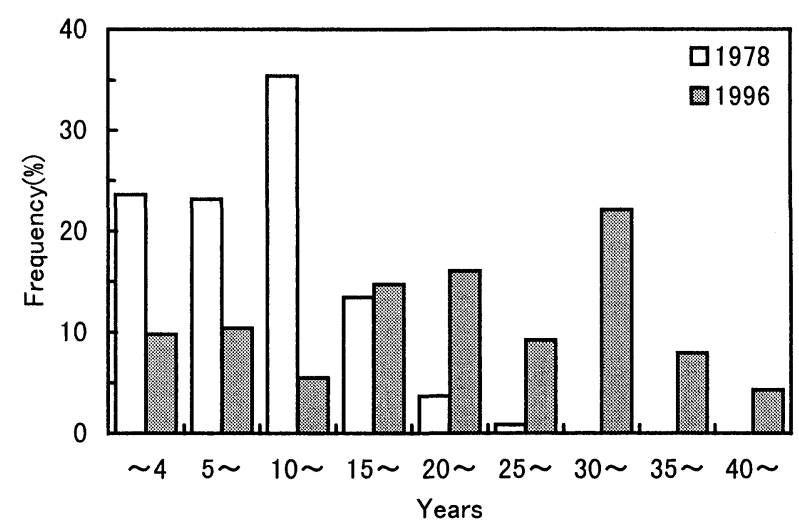

Fig. 4. Distribution of total operating career of vibrating tools

that, the number decreased, but it was still over 500 until 1983. From 1988, it remained at about 300 or less. The rates of workers undergoing medical examinations to forestry workers in Wakayama were between $12.3 \%$ (1990) to 18.7 \% (1980) since 1980.

The age composition was calculated among 1,242 subjects in 1978, 304 subjects in 1988 and 186 subjects in 1996 (Fig. 3). In 1978, the majority of subjects were in their forties (39\%). Next were those in their fifties (36\%). In 1988, the subjects in their fifties were a majority (46\%) and next those in their sixties (34\%). In 1996, the majority of subjects were in their sixties (38\%) and next those in their fifties (26\%). This shows a steady increase in the age level of the subjects examined.

Figure 4 shows the distribution of total operating career of vibrating tools in 1978 and 1996. In 1978, the number of operating years between 10 and 14 years were at a majority $(35 \%)$ and then those less than 5 years (24\%). In 1996, the number of operating years increased. Subjects who had been operating the vibrating tools for 30 years or more stood at $34 \%$.

The major vibrating tools used were counted in 1978 and 1996 (Table 2). In both years, many subjects used chain saws. Eighty percent of the subjects used the chain saws in 1978 and $91 \%$ in 1996. Those who used both a chain saw and a bush cleaner significantly increased from $40 \%$ in 1978 to $65 \%$ in 1996.

A real number of 4,652 (a total of 9,920) subjects received medical examinations for vibration syndrome from 1974 to 1996. Table 3 shows how many times the subjects received medical examinations. Fifty-nine percent of the subjects had received medical examinations only once. Eighty-two percent of the subjects were examined 3 times or less. The mean average was 2.5 times during 23 years. When the 
Table 2. Vibrating tools and the frequencies (\%) of the usage

\begin{tabular}{|c|c|c|c|c|}
\hline & \multicolumn{4}{|c|}{ Year } \\
\hline & \multicolumn{2}{|c|}{1978} & \multicolumn{2}{|c|}{1996} \\
\hline & Subjects & 1,242 & Subjects & 161 \\
\hline Chain saw & & 30.0 & & 22.4 \\
\hline Bush cleaner & & 10.4 & & 6.8 \\
\hline Rock drill & & 3.0 & & 1.9 \\
\hline Chain saw \& Bush cleaner & & 39.4 & & 64.6 \\
\hline Chain saw \& Rock drill & & 0.8 & & 0 \\
\hline Chain saw, Bush cleaner \& Rock d & drill & 1.4 & & 3.7 \\
\hline Others & & 15.0 & & 0.6 \\
\hline Total & & 100.0 & & 100.0 \\
\hline
\end{tabular}

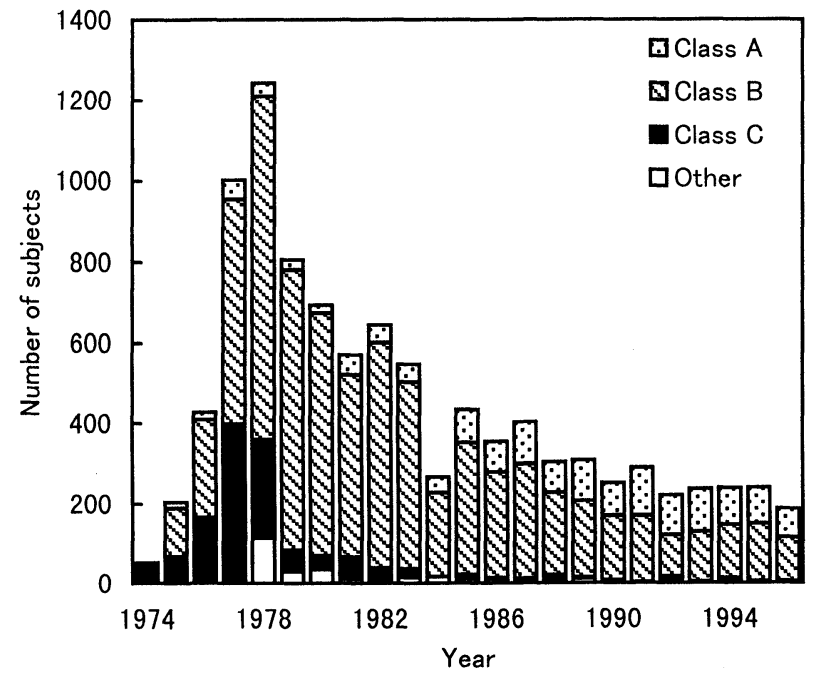

Fig. 5. Trends in the health condition of the subjects by medical examinations for vibration syndrome

subjects were limited to those who had medical examinations in 1996, the average was 7.0 times.

Trends in the health conditions for vibration syndrome are shown in Figure 5. Class $\mathrm{C}$ workers were more than $30 \%$ of subjects examined before 1977. In 1978 and 1979, they drastically decreased and then made up less than $10 \%$. In the last 5 years, the proportion of Class $\mathrm{C}$ workers was $2 \%$. On the contrary, Class A workers totalled less than $10 \%$ of subjects before 1983 . Since then, they have been increasing year by year. In the last 5 years, the proportion of Class A workers was $42 \%$. In relation to this trend, the rates of workers complaining symptoms were also analyzed in 1978, 1988 and 1996. The rates of workers complaining a vibration induced white finger were $25.9 \%$ in $1978,25.7 \%$ in 1988 and $15.1 \%$ in 1996 , respectively. The rates of workers complaining numbness of the finger were $74.7 \%$ in 1978 ,
Table 3. Distribution (\%) of the total subjects by total times of the medical examinations for vibration syndrome

\begin{tabular}{|c|c|c|}
\hline Times & Subjects & 9,920 \\
\hline 1 & & 58.6 \\
\hline 2 & & 16.3 \\
\hline 3 & & 7.3 \\
\hline 4 & & 4.0 \\
\hline 5 & & 3.3 \\
\hline $6-10$ & & 7.0 \\
\hline$\geq 11$ & & 3.5 \\
\hline Total & & 100.0 \\
\hline
\end{tabular}
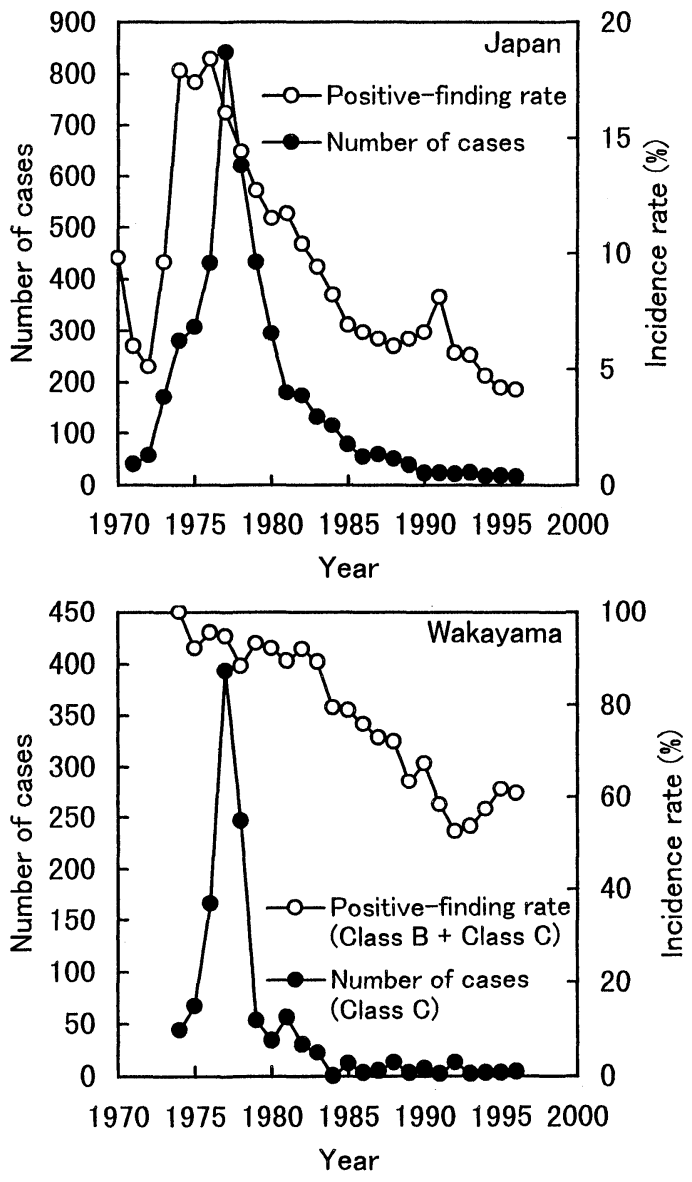

Fig. 6. Trends in the number of compensated cases for vibration syndrome and the positive finding rate of medical examinations in Japan and in Wakayama

$70.4 \%$ in 1988 and $50.5 \%$ in 1996, respectively. The rates were decreasing and answering to the trend.

Figure 6 shows the trends in the number of compensated cases for vibration syndrome and the positive finding rate 
from medical examinations carried out in Japan and in Wakayama. The Worker's Accident Compensation Law Statistics shows that the number of cases of people suffering from vibration syndrome in Japan peaked at 841 in 1978, then it gradually decreased year by year. In the last 10 years, less than 60 cases have been discovered. The number of the cases with Class $\mathrm{C}$ in Wakayama showed a similar trend to that of compensated cases in Japan. It reached a maximum number of 393 cases in 1977, and then decreased year by year. In the last 10 years, there were 13 or less cases. The total number of the cases with Class $C$ was 1,181 . The positive finding rate of medical examinations, Class B and Class C, in Wakayama was much higher than the overal national figure. It has, however, been steadily decreasing year by year.

\section{Discussion}

The Ministry of Labour gave administrative orders for preventive measures against vibration syndrome caused by chain saws in 1970. Then, various administrative orders for preventive measures were enforced to summarize the General Countermeasures against vibration syndrome ${ }^{2)}$. They are outlined under five main headings: (a) vibration reduction of vibrating tools, (b) work control, (c) medical examination and treatment, (d) education for safety and health, (e) investigation and research. The First General Countermeasures have been practiced since 1987 .

In Wakayama, according to the orders of the Ministry of Labour, improvements of forestry working conditions, the traveling guidance for the proper use of vibrating tools and the campaign for taking medical examinations for vibration syndrome have been introduced since $1976^{4}$. However, vibration syndrome commonly occurred at that time. The number of cases suffering from vibration syndrome peaked in Wakayama in 1977.

Concerning the background on the frequent occurrence of vibration syndrome in Wakayama, we can point out the following:

(1) There were so many private forestry workers because forestry is one of the main industries in Wakayama.

(2) These forestry workers have been working in small scale industries, so they have been excluded from the occupational health care system.

(3) Wages have been calculated according to work output, so that getting high wages required longer working hours.

(4) Working environments were uncomfortable; the cold environment of the forests and poor working posture on the slope of mountains.
The regional occupational health care system for vibration syndrome has been active in Wakayama since $1975^{4}$. It is a result of combining the occupational health care system with the regional health care system. It matched the occupational health of small scale industries in local area. Under this system, health care and work control have been practiced strictly according to the diagnosis. Class B workers are permitted to operate vibrating tools for only short periods, or are relocated to a workshop free of exposure to hand-arm vibration. Class $\mathrm{C}$ workers are prohibited from operating vibrating tools and receive necessary medical treatment for their disturbances or disabilities. The number of Class $\mathrm{C}$ workers drastically decreased in 1979, and then totalled less than $10 \%$ among the subjects. This indicates that comprehensive countermeasures, including health care and control of operating hours were effective against vibration syndrome.

As another improvement of the regional occupational health care system for private forestry workers, the health surveillance card (Fig. 7) has been introduced since 1975. It enables us to observe longitudinal changes of circulatory function, nerve function, motor function and symptoms of hands. Forestry workers can utilize these serial findings to keep an eye on health and work conditions. Health management can conduct continuous follow-up for the health conditions of forestry workers or effects of vibration on health. The regional occupational health care system including the surveillance card has probably contributed to the decrease of or prevention of the occurrence of vibration syndrome in Wakayama.

Not only an establishment of the health care system, especially the medical examinations widespread in various workshops requiring vibrating tools, but also an improvement of vibrating tools has played an important role in decreasing vibration syndrome. Vibration acceleration levels of chain saw handles decreased from 3-7 G in 1974 to $1-1.5 \mathrm{G}$ in $1980^{5)}$. Almost all vibration tools have been improved to the level below the allowance level. However, even if the vibration level of tools is below the allowance level, the health effects of long-term exposure to vibration should be considered.

Although the occurrence of severe cases is rare, the vibration syndrome is still one of the most serious occupational diseases in Wakayama. The private forestry workers get older. They are easily affected by the handarm vibration of the tools and by the static muscular loads of the work, showing neck-shoulder-arm syndrome. Thus, a further advanced health care system is needed for private forestry workers operating vibrating tools. 


\begin{tabular}{|c|c|c|c|c|c|c|c|c|c|c|c|c|c|c|}
\hline \multicolumn{4}{|c|}{ Village: Oto village } & \multicolumn{8}{|c|}{ Health surveillance card for vibration syndrome } & \multicolumn{3}{|c|}{ No. } \\
\hline \multirow{3}{*}{$\begin{array}{r}\text { Name } \\
\text { Date }\end{array}$} & \multicolumn{3}{|l|}{ Mr. A, M } & \multirow{2}{*}{\multicolumn{2}{|c|}{$\begin{array}{l}\text { Date of Birth } \\
\text { Function }\end{array}$}} & \multicolumn{2}{|c|}{ 15. 10.1950.} & Sex & Male & \multicolumn{2}{|c|}{ Company } & \multicolumn{3}{|c|}{$\times \times \quad$ Co. Ltd. } \\
\hline & \multirow{2}{*}{$\begin{array}{c}\text { Operating } \\
\text { career }\end{array}$} & \multirow{2}{*}{$\begin{array}{c}\text { Blood } \\
\text { Pressure } \\
\end{array}$} & & & & \multirow{2}{*}{$\begin{array}{l}\text { Muscle } \\
\text { Strength }\end{array}$} & \multirow{2}{*}{$\begin{array}{l}\text { Muscle } \\
\text { Atrophy }\end{array}$} & \multicolumn{2}{|c|}{ Joint disturbances } & \multirow{2}{*}{$\begin{array}{l}\text { Ray. naud } \\
\text { phenom. }\end{array}$} & \multirow{2}{*}{ Numb. } & \multirow{2}{*}{ Pain } & \multirow{2}{*}{ Class } & \multirow{2}{*}{ Note } \\
\hline & & & Circu. & Nerve & Motor & & & Pain & Motor dis. & & & & & \\
\hline Feb. 1986 & BC 5 & $110 / 52$ & +++ & - & + & $\begin{array}{l}\text { r } 37 \\
141 \\
\end{array}$ & $\begin{array}{l}\underline{r}- \\
\underline{1}\end{array}$ & $\underline{\underline{r}}-$ & $\frac{\mathrm{r}}{1}-$ & $\begin{array}{l}\underline{r} \\
\underline{1}\end{array}$ & $\frac{r}{1}-$ & $\frac{\underline{r}}{\underline{1}}-$ & $\mathrm{B}_{1}$ & \\
\hline Jan. 1987 & BC 6 & $94 / 50$ & ++ & + & ++ & $\begin{array}{l}\text { r } 28 \\
133 \\
\end{array}$ & $\underline{\underline{r}}-$ & $\underline{\underline{r}}-$ & $\underline{\underline{r}}-$ & $\underline{\underline{r}}-$ & $\underline{\underline{r}}-$ & $\underline{\underline{r}}-$ & $\mathrm{B}_{1}$ & \\
\hline Feb. 1988 & BC 7 & $120 / 66$ & ++ & - & + & $\begin{array}{l}\text { r } 41 \\
134\end{array}$ & $\underline{\underline{r}}-$ & $\begin{array}{l}\underline{\mathrm{r}}- \\
\underline{1}\end{array}$ & $\frac{\underline{\mathrm{r}}}{\underline{1}}-$ & $\frac{\mathrm{r}}{1}-$ & $\underline{\underline{r}}-$ & $\frac{\mathrm{r}}{1}-$ & A & \\
\hline Jan. 1990 & $\begin{array}{l}\text { CS } 3 \\
\text { BC } 8 \\
\text { Others } 1\end{array}$ & $109 / 63$ & - & - & \pm & $\begin{array}{l}\text { r } 43.5 \\
143.5\end{array}$ & $\frac{\mathrm{r}}{1}-$ & $\frac{\mathrm{r}}{1}-$ & $\underline{\underline{r}}-$ & $\underline{\underline{r}}-$ & $\frac{\mathrm{r}}{1}-$ & $\frac{r}{1}-$ & A & \\
\hline Dec. 1990 & $\begin{array}{l}\text { CS } 4 \\
\text { BC } 9 \\
\text { Others } 2 \\
\end{array}$ & $100 / 40$ & + & - & \pm & $\begin{array}{l}\text { r } 41 \\
137.5\end{array}$ & $\frac{\underline{r}}{1}-$ & $\frac{\underline{r}}{\underline{l}}-$ & $\frac{\underline{r}}{1}-$ & $\frac{\underline{r}}{\underline{l}}-$ & $\begin{array}{c}\underline{\underline{r}}- \\
\underline{1}- \\
\text { shoulder }\end{array}$ & $\frac{\underline{r}}{1}-$ & A & \\
\hline \multirow[t]{3}{*}{ Feb. 1992} & $\begin{array}{l}\text { CS } 5 \\
\text { BC } 10 \\
\text { Others } 4 \\
\end{array}$ & $164 / 44$ & + & + & - & $\begin{array}{l}\text { r } 47 \\
146\end{array}$ & $\frac{\underline{r}}{\underline{l}}-$ & $\frac{\mathrm{r}}{\underline{1}}-$ & $\frac{\underline{r}}{\underline{1}}-$ & $\frac{\underline{r}}{\underline{1}}-$ & $\begin{array}{l}\underline{r}- \\
\underline{1}\end{array}$ & $\frac{\underline{r}}{1}-$ & $\mathrm{A}$ & \\
\hline & & & & & & $\begin{array}{l}\mathrm{r} \\
1\end{array}$ & $\begin{array}{l}\mathrm{r} \\
1\end{array}$ & $\begin{array}{l}\mathrm{r} \\
1\end{array}$ & $\begin{array}{l}\mathrm{r} \\
\mathrm{l}\end{array}$ & $\begin{array}{l}\mathrm{r} \\
1\end{array}$ & $\begin{array}{l}\mathrm{r} \\
1\end{array}$ & $\begin{array}{l}\mathrm{r} \\
1\end{array}$ & & \\
\hline & & & & & & $\begin{array}{l}\mathrm{r} \\
1\end{array}$ & $\begin{array}{l}\mathrm{r} \\
1\end{array}$ & $\begin{array}{l}\mathrm{r} \\
\mathrm{l}\end{array}$ & $\begin{array}{l}\mathrm{r} \\
\mathrm{l}\end{array}$ & $\begin{array}{l}\mathrm{r} \\
\mathrm{l}\end{array}$ & $\begin{array}{l}\mathrm{r} \\
1\end{array}$ & $\begin{array}{l}\mathrm{r} \\
1\end{array}$ & & \\
\hline
\end{tabular}

Fig. 7. Health surveillance card of vibration syndrome

\section{Acknowledgments}

We wish to thank warmly to Prof. Tsutomu Hashimoto, Department of Public Health, Wakayama Medical University, School of Medicine for his taking part in data preparation to make this manuscript.

\section{References}

1) Iwata $H$ (1978) Vibration syndrome. Kindai Press, Tokyo (in Japanese).

2) Labour Standards Bureau, Ministry of Labour (1976-
1997) General guidebook on industrial health. Japan Industrial Safety and Health Association, Tokyo (in Japanese).

3) Miyashita K, Abe M, Iwata H (1988) Occupational health on vibration in Japan. The abstract of the 12th Asian conference on occupational health, Bombay.

4) The panel for countermeasure for vibration syndrome in Wakayama (1980) Guidebook for the countermeasure for vibration syndrome (in Japanese).

5) Futatsuka M, Ueno T, Yamada S (1994) Vibration exposure and prevention in Japan. Nagoya J Med Sci 57 (suppl.), 195-202. 